\title{
Hydrogen sulfide and sodium nitroprusside compete to activate/deactivate MMPs in bone tissue homogenates
}

This article was published in the following Dove Press journal:

Vascular Health and Risk Management

18 March 2013

Number of times this article has been viewed

\author{
Thomas P Vacek \\ Natia Qipshidze \\ Suresh C Tyagi \\ Department of Physiology and \\ Biophysics, University of Louisville \\ School of Medicine, Louisville, KY, \\ USA
}

Correspondence: Suresh C Tyagi University of Louisville, Department of Physiology and Biophysics, 500 South Preston Street, HSC BIdg A, Room 1215, Lousville, KY 40202, USA

$\mathrm{Tel}+\mathrm{I} 502852338$ I

Fax + I 5028526239

Emails0tyag0।@louisville.edu
Background: Bone microvascular remodeling is the primary predictor of bone structure and function. Remodeling by its very nature implies synthesis and degradation of the extracellular matrix. Normally, $50 \%$ of total protein in the vessel wall is elastin. During remodeling, elastin is degraded by specialized matrix metalloproteinases (MMPs). Because the turnover of elastin is 1000 -fold slower than that of collagen, most of the elastin is replaced by stiffer collagen. Stiffer vessels impose pressure on the aortic valve, causing regurgitation and increased pulse pressure. On the other hand, high MMP activity will cause vascular dilatation, leading to aneurysm. Therefore, balanced constitutive remodeling is necessary for adequate bone structure and function. Interestingly, collagen-degrading MMPs are involved in various pathological conditions, including osteoporosis, osteoarthritis, and cardiovascular disease. Sodium nitroprusside is a nitric oxide donor that could potentially alter MMP activity via vasodilation in vivo, but can also produce peroxynitrite, which activates MMPs by combining with superoxide. Moreover, hydrogen sulfide is a known antioxidant as well as a vasodilator, and is also speculated to contribute directly to MMP activity. We hypothesized that hydrogen sulfide reduced activity of MMP in ex vivo bone tissue homogenates and that sodium nitroprusside would increase MMP activity in vitro.

Methods: We surgically removed the tibia and femur from anesthetized mice, and prepared bone tissue homogenates using a mortar and pestle, measured the protein concentration with a spectrophotometer, and detected MMP activity using gelatin gel zymography.

Results: Our data showed increased MMP activity at a sodium nitroprusside concentration of $1 \mu \mathrm{M}$, and MMP activity increased exponentially. There was a decrease in MMP activity with increasing hydrogen sulfide, beginning at $16 \mu \mathrm{M}(P<0.01)$ and continuing to $40 \mu \mathrm{M}$. Moreover, sodium nitroprusside $3 \mu \mathrm{M}$ was able to overcome the decrease in MMP activity that occurred with hydrogen sulfide $40 \mu \mathrm{M}$; this resulted in a more pronounced exponential increase in MMP activity.

Conclusion: There are several substances that can potentially be used to decrease MMP activity and to alleviate pathological remodeling by MMPs.

Keywords: homocysteine, matrix metalloproteinases, oxidative stress, bone remodeling, collagen cross-linking

\section{Introduction}

Matrix metalloproteinases (MMPs) are membrane-bound, zinc-dependent endoproteinases with three major subtypes, ie, interstitial collagenases, gelatinases, and stromelysins. ${ }^{1}$ Several MMPs are expressed and activated in many organs and tissue in different pathological conditions. This has been researched in the cardiovascular 
and skeletal system. ${ }^{2,3}$ The collagenases, MMP-1,-13, -2, and -9 are major players in the digestion of bone matrix by osteoblasts. $^{4,5}$

Our laboratory has worked extensively with the molecule, homocysteine, an amino acid derivative that has been shown to increase oxidative stress within cells and subsequently to activate MMPs. ${ }^{6,7}$ Homocysteine has a remarkable effect on the cardiovasculature by vasoconstriction and decreasing blood flow. Homocysteine is also known to increase oxidative stress within cells. In order to combat this, our laboratory has sought to identify specific vasorelaxant molecules that can relieve oxidative stress.

Hydrogen sulfide is a known antioxidant and acts as a vasorelaxant to relieve oxidative stress. To date, the evidence has been conflicting with regard to the use of hydrogen sulfide as a beneficial substrate to combat oxidative stress in such situations as interventional stress ${ }^{8}$ and oxidative stress created by homocysteine. However, when analyzing the relevant studies further, it appears that the debate rests largely on the concentration used. In a follow-up study to determine whether hydrogen sulfide protects against vascular remodeling as a result of endothelial damage, we aimed to discover whether varying concentrations of hydrogen sulfide can affect the activity of MMPs in bone. To do this, we purified a control bone sample as a source of MMPs and treated this sample with varying concentrations of hydrogen sulfide. Because hydrogen sulfide acts as an antioxidant at lower concentrations, we hypothesized that it would neutralize free radicals in solution and deactivate MMPs at low concentrations.

Nitric oxide also acts to relieve vasoconstriction and increase blood flow, thereby relieving oxidative stress. However, nitric oxide can react with superoxides in solution to form peroxynitrite that can activate MMPs. Therefore, we hypothesized that nitric oxide may have some beneficial role in vivo. However, direct molecular exposure to nitric oxide can have detrimental consequences with respect to activation of MMP.

The interaction between hydrogen sulfide and nitric oxide is complex. Under some circumstances, it has been shown that hydrogen sulfide acts as a peroxynitrite scavenger. ${ }^{9}$ A peroxynitrite scavenger serves to inhibit MMP activation because the peroxynitrite radical can activate MMPs. ${ }^{9}$ Consistent with this, hydrogen sulfide has been shown to have both proinflammatory and anti-inflammatory activity ${ }^{10,11}$ in antioxidizing and oxidizing environments. In one of our projects, we hypothesized that damaging conditions would increase pathological remodeling prompted by activation of MMP-2; further, we questioned whether hydrogen sulfide alleviates this activation. ${ }^{8}$ In fact, it was shown that this was the case. In this experiment, we also aimed to discover at what concentration nitric oxide might overcome the ability of hydrogen sulfide to activate MMPs and how this would appear.

One study has indicated that the nitric oxide pathway decreased expression of MMP-2 induced by interleukin-1 $\beta$ in human cardiac fibroblasts, ${ }^{12}$ and another study confirmed an increase in MMP-9 expression and activity in aortic smooth muscle cells after inhibition of nitric oxide synthase. ${ }^{13}$ Hence it appears that nitric oxide has some in vivo effect in decreasing MMP activity. However, it is also known that nitric oxide donors can combine with superoxide to produce peroxynitrite that can activate MMPs. ${ }^{14}$ We aimed to determine the result of adding sodium nitroprusside to lysed bone homogenates containing MMP protein.

\section{Materials and methods Animals}

The mice used in this experiment were obtained from Jackson Laboratories (Bar Harbor, ME, USA) and housed in the animal care facility at the University of Louisville. All animal procedures were carried out in accordance with the National Institute of Health Guidelines for animal research. The Institutional Animal Care and Use Committee of the University of Louisville, School of Medicine, approved the protocol.

\section{Bone homogenates}

The tibia and femurs were extracted surgically from each mouse, placed in phosphate-buffered solution, and put into a refrigerator. The extra tissue attached to the bones was easily removed using KimWipes ${ }^{\circledR}$ (Kimberly-Clark Professional, West Malling, UK) and the bones were then stored at $-20^{\circ} \mathrm{C}$ until ready for further processing. The bones were placed in a mortar, and T-Pur ${ }^{\circledR}$ buffer solution (Thermo Scientific, Barrington, IL, USA) was added at a volume of $150 \mu \mathrm{L}$ per bone. The mortar was then placed in a Styrofoam ${ }^{\mathrm{TM}}$ (The Dow Chemical Company, Midland, MI, USA) container with a bottom layer containing liquid nitrogen. The bone and buffer was allowed to freeze in the container of liquid nitrogen for 7 minutes. A pestle was then carefully used to grind the frozen bone/buffer. This was performed for 5-10 minutes. The resulting frozen pulverized bone was placed in a $1.5 \mathrm{~mL}$ Eppendorf tube and placed on a rotating device in a cold storage room at $4^{\circ} \mathrm{C}$ overnight. The next day, the Eppendorf tube was centrifuged twice at $13,000 \mathrm{rpm}$ for 10 minutes at $4^{\circ} \mathrm{C}$, each time extracting the supernatant and discarding the pellet. 


\section{Gelatin gel zymography}

MMP-9 activity was measured using gelatin gel zymography. Ten percent sodium dodecyl sulfate gels were prepared containing $0.1 \%$ heat-dissolved gelatin. The protein content was estimated using the Bradford dye protocol and a spectrophotometer. Next, $150 \mu \mathrm{g}$ of the sample were added to the Eppendorf tubes. The tubes were kept on ice, and appropriate amounts of hydrogen sulfide and sodium nitroprusside were added to each tube to make up the desired concentrations. After one hour, appropriate amounts of $2 \times$ zymography dye were added. The samples were vortexed and allowed to set for another 10 minutes before loading into wells in the gel. The container with gels and running buffer was placed in a tray and surrounded by ice. A $1 \times$ Tris-glycine running buffer ( $\mathrm{pH} 8.3$ ) was used. The voltage was first turned to $70 \mathrm{~V}$ until the protein was stacked appropriately, and then increased to $125 \mathrm{~V}$. The run time was approximately 2 hours, by which time the dye had ran out of the gel. The gels were then subjected to two 25 -minute washes using $1 \%$ Triton in distilled water to remove any remaining sodium dodecyl sulfate in the gels. The gels were then rinsed briefly in distilled water to remove any remaining froth from the Triton, put into developing buffer, and placed in a water bath incubator overnight. The developing buffer was replaced after 24 hours and the samples were incubated again overnight. The gels were developed the following morning using Coomassie Blue R-250 for 30 minutes, then destained with Coomassie R-250 destaining solution (ratio of methanol to acetic acid to water, 50:10:40). The bands were then scanned using a gel scanner. Intensities were analyzed using software analysis.

Values are reported as the mean and standard error for the four groups. A Student's $t$-test was used to compare the group means, and results were considered to be statistically significant at $P<0.05$.

\section{Results}

The control mouse bone homogenates treated with varying concentrations of sodium nitroprusside showed an exponential increase in MMP activity, which was statistically significant at as little as $1 \mu \mathrm{M}(24 \%$ greater than control, $P<0.05), 2 \mu \mathrm{M}$ (65\% greater than control, $P<0.05), 3 \mu \mathrm{M}$ (73\% greater than control, $P<0.05), 4 \mu \mathrm{M}(91 \%$ greater than control, $P<0.05)$, and $8 \mu \mathrm{M}(92 \%$ greater than control, $P<0.05)$, as shown in Figure 2.

When the control mouse bone homogenates were treated with varying concentrations of hydrogen sulfide, there was a decrease in MMP activity starting at $16 \mu \mathrm{M}$ with 0.72 of the control value $(P<0.01)$ and continued in a linear manner at
MMP activity $\mathrm{H}_{2} \mathrm{~S}$

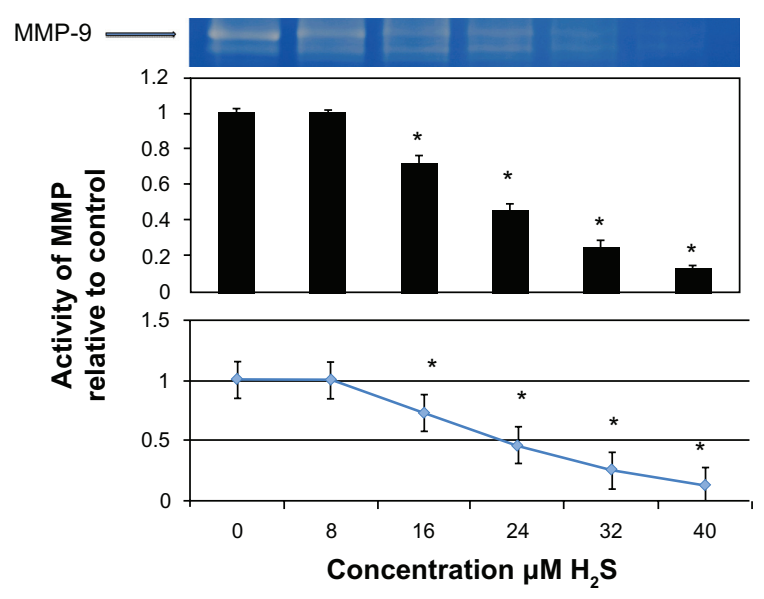

Figure I MMP activity with $\mathrm{H}_{2} \mathrm{~S}$.

Notes: MMP activity decreases with increasing $\mathrm{H}_{2} \mathrm{~S}$ concentration. A significant decrease starts at $16 \mu \mathrm{M}$ and continues to decrease at 24,32 , and $40 \mu \mathrm{M}$ with a constant slope.

Abbreviations: MMP, matrix metalloproteinase; $\mathrm{H}_{2} \mathrm{~S}$, hydrogen sulfide.

$24 \mu \mathrm{M}$ with 0.45 of the control $(P<0.01), 32 \mu \mathrm{M}$ with 0.25 of the control $(P<0.01)$, and $40 \mu \mathrm{M}$ with 0.13 of control $(P<0.01)$. The slope of change beginning with $16 \mu \mathrm{M}$ was approximately the same (Figure 1). In the graph showing competition of nitric oxide and hydrogen sulfide, a hydrogen sulfide concentration of $40 \mu \mathrm{M}$ decreased the activity of MMPs, and varying concentrations of sodium nitroprusside were added to the solution. There was an increasing trend of MMP activity that did not reach statistical significance

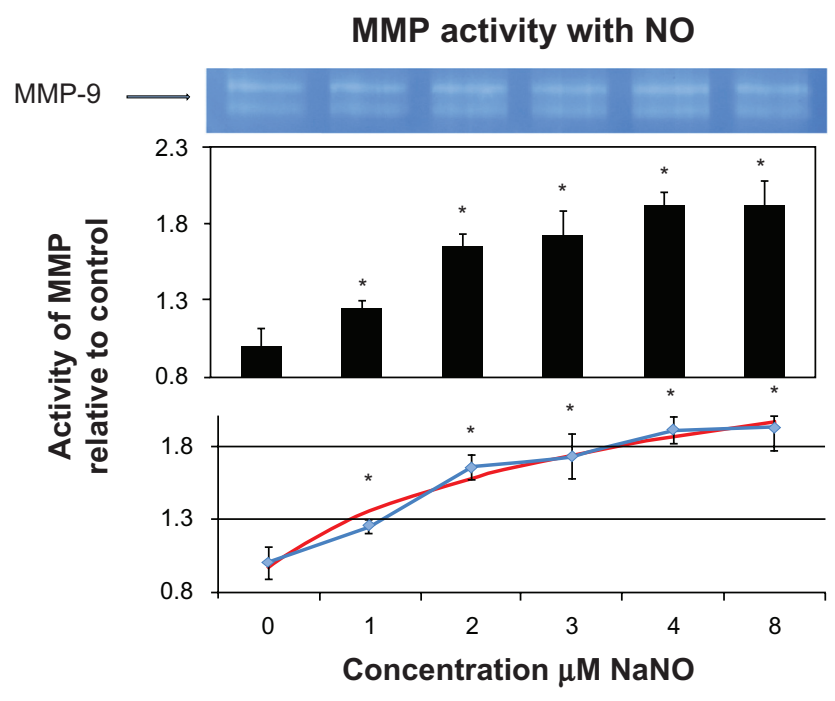

Figure 2 MMP activity with NO.

Notes: MMP activity increases with increasing NO concentration that begins at I $\mu \mathrm{M}$ and increases exponentially with each $\mu \mathrm{M}$ added. $\mathrm{A}$ trend line is added that shows this exponential increase.

Abbreviations: MMP, matrix metalloproteinase; $\mathrm{NO}$, nitric acid; $\mathrm{NaNO}$, sodium nitroprusside. 
with addition of sodium nitroprusside $1 \mu \mathrm{M}$ or $2 \mu \mathrm{M}$ combined with hydrogen sulfide $40 \mu \mathrm{M}$ when compared with the hydrogen sulfide $40 \mu \mathrm{M}$ control. Sodium nitroprusside $2 \mu \mathrm{M}$ increased activity levels by two-fold compared with the hydrogen sulfide $40 \mu \mathrm{M}$ control. A significant exponential increase was noted with sodium nitroprusside $3 \mu \mathrm{M}$ and $4 \mu \mathrm{M}$, with activity values reaching that of the original control values $(P<0.01$, Figure 3$)$.

\section{Discussion}

Our data suggest that MMPs in mitochondria are activated by peroxynitrite, causing cardiovascular remodeling and failure. ${ }^{15}$ Moreover, it is known that sodium nitroprusside is a nitric oxide donor that combines with superoxide in solution to produce peroxynitrite. Hence, our results showing increased MMP activity with cleavage of proMMP to active MMP are logical. This started at sodium nitroprusside concentrations of only $1 \mu \mathrm{M}(P<0.05)$ and proceeded further at concentrations of $2 \mu \mathrm{M}, 3 \mu \mathrm{M}, 4 \mu \mathrm{M}$, and $8 \mu \mathrm{M}$. However, the difference in activity between the $4 \mu \mathrm{M}$ and $8 \mu \mathrm{M}$ concentrations was not significant with increasing concentration. Maximum activity was reached at $4 \mu \mathrm{M}(P<0.05)$, and was also noted to be exponential at this concentration (Figure 2). Further, hydrogen sulfide is a known antioxidant that neutralizes free radicals. This neutralization is hypothesized to deactivate MMPs, and is in accordance with our results, whereby as little as $16 \mu \mathrm{M}$ of hydrogen sulfide could decrease MMP activity $(P<0.05)$. This decrease in MMP activity was noted to have a direct

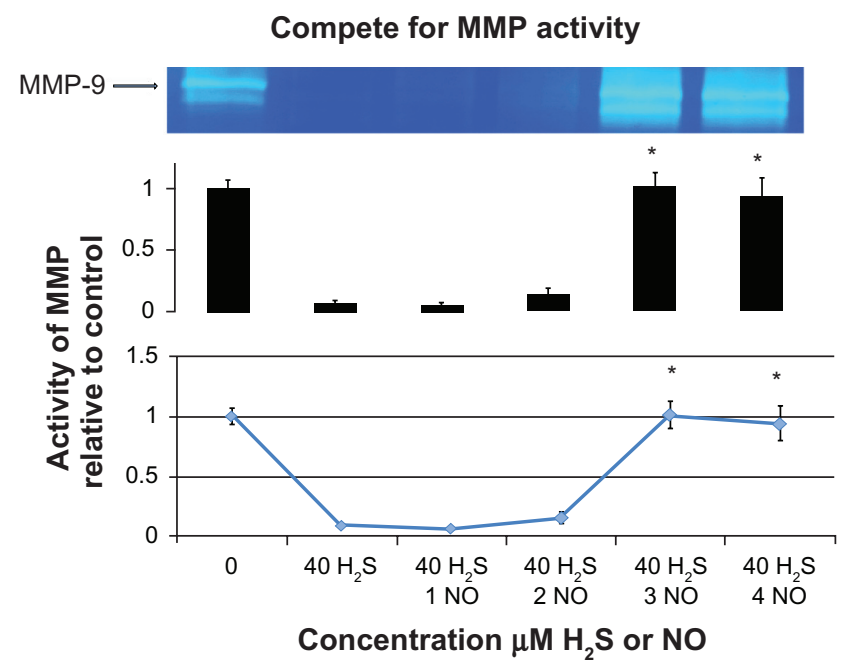

Figure $3 \mathrm{H}_{2} \mathrm{~S}$ competes to activate/deactivate MMP activity.

Notes: With $40 \mu \mathrm{M}$ of $\mathrm{H}_{2} \mathrm{~S}$ added to the solution, MMP activity is turned off. However, as sodium nitroprusside is added, there is an exponential increase in MMP activity. Abbreviations: MMP, matrix metalloproteinase; $\mathrm{NO}$, nitric acid; $\mathrm{H}_{2} \mathrm{~S}$, hydrogen sulfide. linear relationship, with a virtually unchanging slope, as shown in Figure 1. The literature shows that homocysteine is capable of generating hydrogen sulfide if cystathionine beta synthase and cystathionine gamma lyase are present, ${ }^{15}$ and hydrogen sulfide has been shown to be a strong antioxidant and vasorelaxant. Cystathionine gamma lyase is found in all tissues, whereas cystathionine beta synthase is not, so only $50 \%$ of the homocysteine can be converted to hydrogen sulfide. ${ }^{15}$ It is plausible that in these circumstances the body attempts to neutralize the oxidative stress in this environment. This makes sense, given that oxidative stress has been shown to create a pathological MMP profile. ${ }^{6}$

Reactive oxygen and nitrogen species generate nitrotyrosine and are able to activate latent resident MMPs. ${ }^{16}$ Treatment with a hydrogen sulfide donor mitigates generation of nitrotyrosine and activation of MMP. Tissue inhibitor of metalloproteinases (TIMP)-1 and TIMP-3 levels were increased, while TIMP-4 was decreased. ${ }^{16}$ Treatment with a hydrogen sulfide donor prevented fibrosis, apoptosis, and the decrease in integrin. ${ }^{16}$ Hence, hydrogen sulfide is important in neutralizing free radical species.

In one of our studies, we aimed to examine the differential role of MMPs versus TIMP in vascular remodeling. We concluded that p47, TIMP-3, MMP-9, and MMP-12 were increased while superoxide dismutase-1, MMP-2, and TIMP-4 were decreased in the injured arteries. Treatment with hydrogen sulfide made this damage less severe by normalizing redox stress, MMP, and TIMP levels. ${ }^{8}$ However, our laboratory wanted to know if hydrogen sulfide has a direct role on the enzyme itself, without stimulating any particular cellular environment. Hence, we aimed to use tissue homogenates with lysed cells to perform our experiments.

In one of the experiments in our laboratory, we discovered that sodium hydrogen sulfide was able to enhance the inhibitory effects of $\mathrm{N}$-acetyl-L-cysteine, glutathione, catalase, superoxide dismutase, and Nomega-nitro-L-arginine methyl ester on production of reactive oxygen species. Physiological concentrations of hydrogen sulfide have been shown to be 45-300 $\mu \mathrm{M} .{ }^{17,18}$ However, we found a decrease in MMPs at even lower concentrations, starting at $16 \mu \mathrm{M}$ and a very pronounced effect was seen at $40 \mu \mathrm{M}$. This is consistent with the current thought in the literature that lower physiological concentrations of hydrogen sulfide are beneficial. At these physiological concentrations, hydrogen sulfide inhibits proliferation of smooth muscle cells using the mitogen-activated protein kinase pathway. This is known to protect neurons, cardiomyocytes, beta cells in the pancreas, and vascular smooth muscle cells. ${ }^{19}$ Moreover, hydrogen sulfide can act 
as an endogenous scavenger for reactive nitrogen and oxygen species. $^{20-22}$

Our laboratory has also shown that sodium hydrogen sulfide is able to attenuate methionine-induced peroxynitrite formation. Generation of $\mathrm{ONOO}-$ requires rapid interaction of nitric oxide and $\mathrm{O}^{2-}$. When adding sodium hydrogen sulfide, there was a decrease in production of reactive oxygen species. ${ }^{23}$ Moreover, it was shown that hydrogen sulfide reacts with at least four different types of reactive oxygen species, ie, superoxide radicals, hydrogen peroxide, peroxynitrite, and hypochlorite, ${ }^{20,21,24}$ as shown in Figure 4. It was also discovered that hydrogen sulfide enhances production of nitric oxide, with half-activation of mitogen-activated protein kinase in vivo, suggesting that hydrogen sulfide may cooperate with nitric oxide. However, in the human body, this balance would be a complex one, with high levels of hydrogen sulfide inducing reactive oxygen and nitrogen species and low levels decreasing generation of $\mathrm{H}_{2} \mathrm{O}_{2}, \mathrm{ONOO}-$, and $\mathrm{O}^{2-} \cdot{ }^{24}$ We chose an 8-40 $\mu \mathrm{M}$ concentration range in order to produce a beneficial effect of decreasing MMPs. In fact, the highest concentration we used was in the range of the lower physiological concentration of hydrogen sulfide that is known to have beneficial effects.
One study using glioma cell lines showed that treatment with sodium nitroprusside, a nitric oxide donor, induced MMP-1 mRNA, secreted MMP-1 protein, and motility of glioma cell lines. ${ }^{25}$ Another study showed that a drug inhibiting nitric oxide also inhibited MMP-2 activity via interleukin- $1 \beta$ in a nitric oxide-dependent pathway. ${ }^{12,26}$ Another study showed that inhibition of inducible nitric oxide synthase or treatment with superoxide dismutase reduced MMP-9 protein and activity in rat cardiac allografts, and this situation was also accompanied by reduced production of nitrotyrosine and superoxide. ${ }^{27}$

In contrast with these studies, primary rat astrocytes stimulated with lipopolysaccharide were found to overexpress MMP-9 and nitric oxide, and inhibition of nitric oxide using Nomega-nitro-L-arginine methyl ester increased MMP-9 expression. This suggests that nitric oxide inhibited MMP-9 expression. The same study treated cells with sodium nitroprusside and showed inhibition of MMP-9 expression in astrocytes. ${ }^{28}$ Hence, there is a complex role between hydrogen sulfide and nitric oxide that needs to be examined further, and the balance between these molecules in the activation of MMP is shown in Figure 5. Hydrogen sulfide inhibits oxidative stress, thereby inhibiting activation of MMP and destruction of the collagen helix. In our experiment, we used

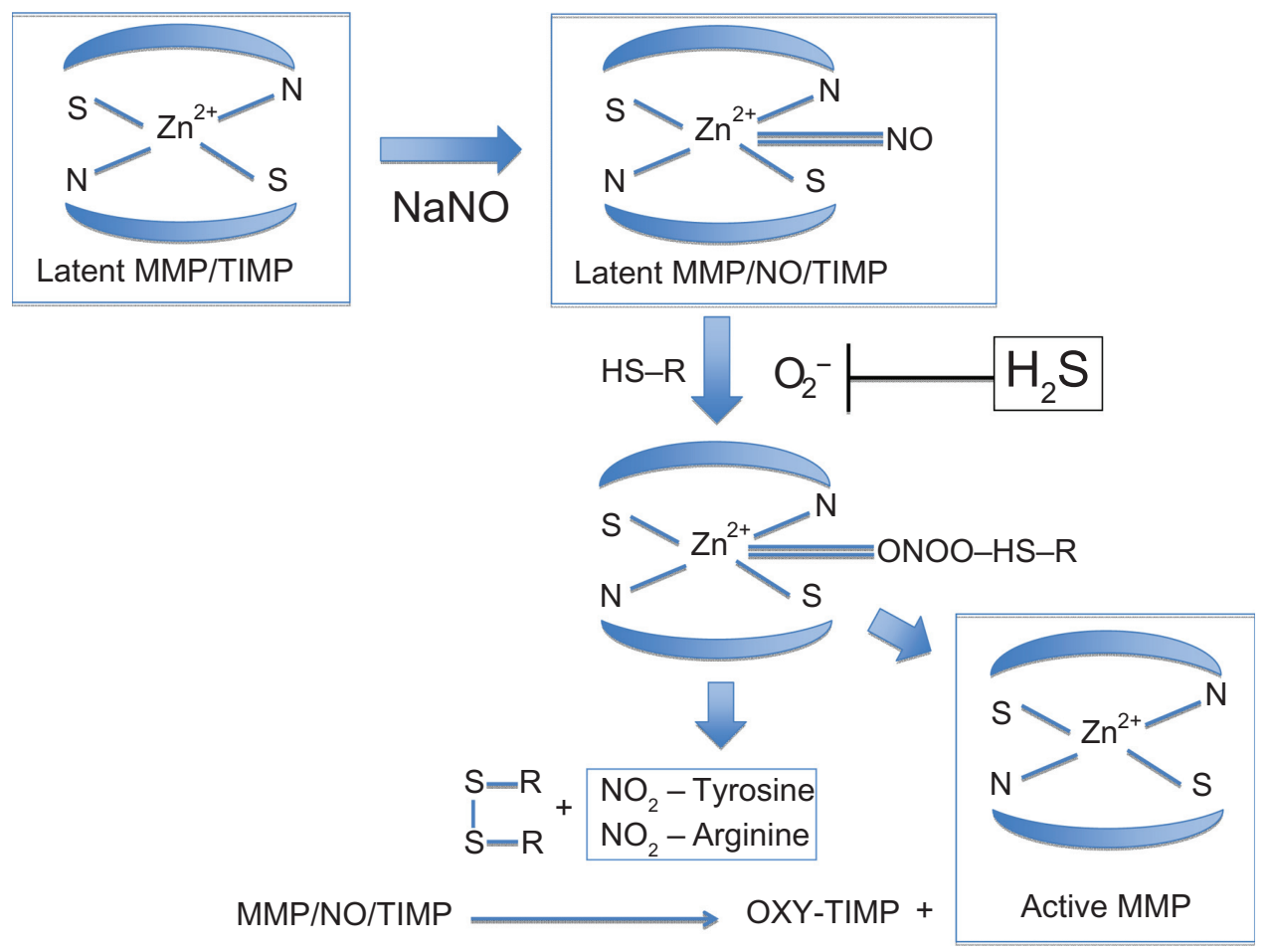

Figure 4 Conversion of latent MMP to active MMP.

Notes: MMP accepts NO, and combines with superoxide to form peroxynitrite that cleaves latent MMP into active MMP. MMP/NO/TIMP proceeds to oxidized TIMP and active MMP.

Abbreviations: MMP, matrix metalloproteinase; $\mathrm{NO}$, nitric acid; $\mathrm{NaNO}$, sodium nitroprusside; $\mathrm{H}_{2} \mathrm{~S}$, hydrogen sulfide; TIMP, tissue inhibitor of metalloproteinases. 


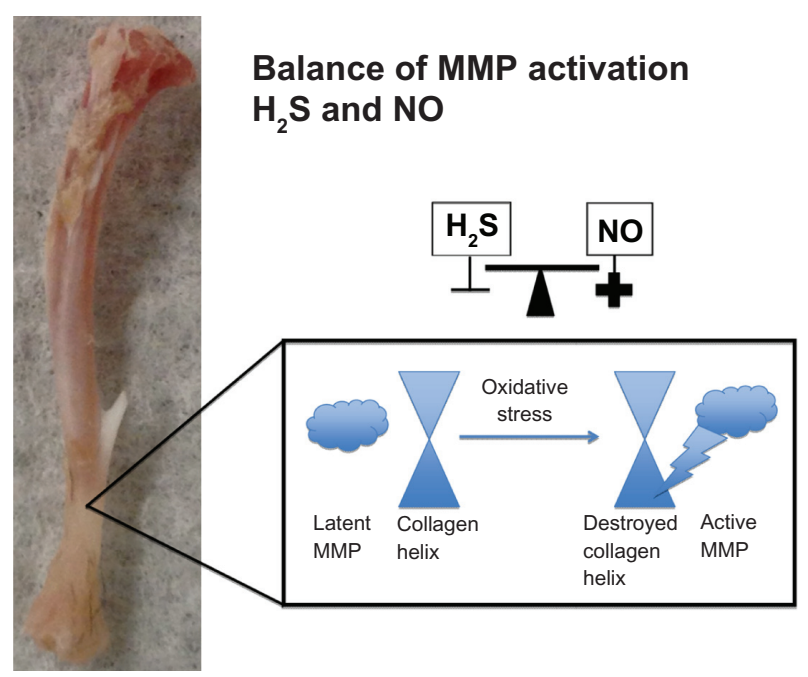

Figure 5 Balance of MMP activation with $\mathrm{H}_{2} \mathrm{~S}$ and $\mathrm{NO}$.

Notes: $\mathrm{H}_{2} \mathrm{~S}$ inhibits conversion of latent MMP to active MMP as well as destruction of the collagen helix caused by oxidative stress. NO promotes oxidative stress by combining with superoxide and forming peroxynitrite, thereby encouraging conversion of latent MMP to active MMP and destruction of the collagen helix. Abbreviations: MMP, matrix metalloproteinase; $\mathrm{NO}$, nitric acid; $\mathrm{H}_{2} \mathrm{~S}$, hydrogen sulfide.

a $40 \mu \mathrm{M}$ concentration of sodium hydrogen sulfide that is known to decrease MMPs dramatically. From this concentration, we made sodium nitroprusside $1 \mu \mathrm{M}, 2 \mu \mathrm{M}, 3 \mu \mathrm{M}$, and $4 \mu \mathrm{M}$ concentrations. There were significant increases from control when just $1 \mu \mathrm{M}$ of sodium nitroprusside was added to the suspension of bone protein in hydrogen sulfide. However, the increase in activity became exponential at a sodium nitroprusside concentration of $3 \mu \mathrm{M}$, as shown in Figure 3.

\section{Conclusion}

This experiment shows the direct effects of hydrogen sulfide and nitric oxide on MMP-9 activity at a molecular level, as well as the direct effects of competition between hydrogen sulfide and nitric oxide in solution. Addition of sodium nitroprusside produced an exponential increase in MMP-9 activity, whereas addition of sodium hydrogen sulfide produced a linear decrease in MMP-9 activity. Sodium nitroprusside restored MMP-9 activity after addition of sodium hydrogen sulfide, and this increase in activity had an exponential relationship. Further studies are warranted in cell culture and in vivo to examine this balance in more detail. Although hydrogen sulfide and nitric oxide may have a direct effect on the MMP enzyme, these effects may not be the same in vivo. It is crucial to find treatments that place this balance in a clinically beneficial skew for patients in need of care.

\section{Acknowledgment}

Part of this study was supported by grants HL-74185, HL-108621, and NS-51568 from the National Institutes of Health.

\section{Disclosure}

The authors report no conflicts of interest in this work.

\section{References}

1. Renaud S, Leppert D. Matrix metalloproteinases in neuromuscular disease. Muscle Nerve. 2007;36:1-13.

2. Mauney J, Volloch V. Adult human bone marrow stromal cells regulate expression of their MMPs and TIMPs in differentiation type-specific manner. Matrix Biol. 2010;29:3-8.

3. Dreger SA, Taylor PM, Allen SP, Yacoub MH. Profile and localization of matrix metalloproteinases (MMPs) and their tissue inhibitors (TIMPs) in human heart valves. J Heart Valve Dis. 2002;11:875-880.

4. Heath JK, Atkinson SJ, Meikle MC, Reynolds JJ. Mouse osteoblasts synthesize collagenase in response to bone resorbing agents. Biochim Biophys Acta. 1984;802:151-154.

5. Kusano K, Miyaura C, Inada M, et al. Regulation of matrix metalloproteinases (MMP-2, -3, -9, and -13) by interleukin-1 and interleukin- 6 in mouse calvaria: association of MMP induction with bone resorption. Endocrinology. 1998;139:1338-1345.

6. Tyagi N, Kandel M, Munjal C, et al. Homocysteine mediated decrease in bone blood flow and remodeling: role of folic acid. J Orthop Res. 2011;29:1511-1516.

7. Moshal KS, Singh M, Sen U, et al. Homocysteine-mediated activation and mitochondrial translocation of calpain regulates MMP-9 in MVEC. Am J Physiol Heart Circ Physiol. 2006;291:H2825-H2835.

8. Vacek T, Gillespie W, Tyagi N, Vacek J, Tyagi S. Hydrogen sulfide protects against vascular remodeling from endothelial damage. Amino Acids. 2010;39:1161-1169.

9. Whiteman M, Armstrong JS, Chu SH, et al. The novel neuromodulator hydrogen sulfide: an endogenous peroxynitrite 'scavenger'? J Neurochem. 2004;90:765-768.

10. Bhatia M. Hydrogen sulfide and substance $P$ in inflammation. Antioxid Redox Signal. 2010;12:1191-1202.

11. Whiteman M, Li L, Rose P, Tan CH, Parkinson DB, Moore PK. The effect of hydrogen sulfide donors on lipopolysaccharide-induced formation of inflammatory mediators in macrophages. Antioxid Redox Signal. 2010;12:1147-1154.

12. Guo XG, Uzui H, Mizuguchi T, Ueda T, Chen JZ, Lee JD. Imidaprilat inhibits matrix metalloproteinase- 2 activity in human cardiac fibroblasts induced by interleukin-1 beta via NO-dependent pathway. Int $J$ Cardiol . 2008; 126:414-420.

13. Knipp BS, Ailawadi G, Ford JW, et al. Increased MMP-9 expression and activity by aortic smooth muscle cells after nitric oxide synthase inhibition is associated with increased nuclear factor-kappaB and activator protein-1 activity. $J$ Surg Res. 2004;116:70-80.

14. Guzik TJ, West NE, Pillai R, Taggart DP, Channon KM. Nitric oxide modulates superoxide release and peroxynitrite formation in human blood vessels. Hypertension. 2002;39:1088-1094.

15. Tyagi N, Mishra PK, Tyagi SC. Homocysteine, hydrogen sulfide $\left(\mathrm{H}_{2} \mathrm{~S}\right)$ and NMDA-receptor in heart failure. Indian J Biochem Biophys. 2009;46:441-446.

16. Mishra PK, Tyagi N, Sen U, Givvimani S, Tyagi SC. $\mathrm{H}_{2} \mathrm{~S}$ ameliorates oxidative and proteolytic stresses and protects the heart against adverse remodeling in chronic heart failure. Am J Physiol Heart Circ Physiol. 2010;298:H451-H1456.

17. Yang G, Cao K, Wu L, Wang R. Cystathionine gamma-lyase overexpression inhibits cell proliferation via a $\mathrm{H}_{2} \mathrm{~S}$-dependent modulation of ERK1/2 phosphorylation and p21Cip/WAK-1. J Biol Chem. 2004;279:49199-49205. 
18. Yu BP. Cellular defenses against damage from reactive oxygen species. Physiol Rev. 1994;74:139-162.

19. Kimura Y, Dargusch R, Schubert D, Kimura H. Hydrogen sulfide protects HT22 neuronal cells from oxidative stress. Antioxid Redox Signal. 2006;8:661-670.

20. Geng B, Yang J, Qi Y, et al. $\mathrm{H}_{2} \mathrm{~S}$ generated by heart in rat and its effects on cardiac function. Biochem Biophys Res Commun. 2004;313: 362-368.

21. Geng B, Chang L, Pan C, et al. Endogenous hydrogen sulfide regulation of myocardial injury induced by isoproterenol. Biochem Biophys Res Commun. 2004;318:756-763.

22. Wang R. Two's company, three's a crowd: can $\mathrm{H}_{2} \mathrm{~S}$ be the third endogenous gaseous transmitter? FASEB J. 2002;16:1792-1798.

23. Tyagi N, Moshal KS, Sen U, et al. $\mathrm{H}_{2} \mathrm{~S}$ protects against methionineinduced oxidative stress in brain endothelial cells. Antioxid Redox Signal. 2009;11:25-33.

24. Tyagi N, Moshal KS, Tyagi SC, Lominadze D. Gamma-aminbuturic acid A receptor mitigates homocysteine-induced endothelial cell permeability. Endothelium. 2007;14:315-323.
25. Pullen NA, Fillmore HL. Induction of matrix metalloproteinase-1 and glioma cell motility by nitric oxide. J Neurooncol. 2010;96: 201-209.

26. Guo XG, Uzui H, Mizuguchi T, Ueda T, Chen JZ, Lee JD. Imidaprilat inhibits matrix metalloproteinase-2 activity in human cardiac fibroblasts induced by interleukin-1 beta via NO-dependent pathway. Int $J$ Cardiol . 2008; 126:414-420.

27. Egi K, Conrad NE, Kwan J, Schulze C, Schulz R, Wildhirt SM. Inhibition of inducible nitric oxide synthase and superoxide production reduces matrix metalloproteinase- 9 activity and restores coronary vasomotor function in rat cardiac allografts. Eur J Cardiothorac Surg. 2004;26:262-269.

28. Shin CY, Lee WJ, Choi JW, et al. Down-regulation of matrix metalloproteinase- 9 expression by nitric oxide in lipopolysaccharide-stimulated rat primary astrocytes. Nitric Oxide. 2007;16:425-432.
Vascular Health and Risk Management

\section{Publish your work in this journal}

Vascular Health and Risk Management is an international, peerreviewed journal of therapeutics and risk management, focusing on concise rapid reporting of clinical studies on the processes involved in the maintenance of vascular health; the monitoring, prevention and treatment of vascular disease and its sequelae; and the involvement of

\section{Dovepress}

metabolic disorders, particularly diabetes. This journal is indexed on PubMed Central and MedLine. The manuscript management system is completely online and includes a very quick and fair peer-review system, which is all easy to use. Visit http://www.dovepress.com/ testimonials.php to read real quotes from published authors.

Submit your manuscript here: http://www.dovepress.com/vascular-health-and-risk-management-journal 